\title{
Physicians' Knowledge and Awareness about Biosimilars in Saudi Arabia: What is Imperative to Know ??
}

\author{
Ziyad Saeed Almalki ${ }^{1}$, Muhammad Shahid Iqbal ${ }^{1, *}$, Manal Abdullah Alossaimi ${ }^{2}$, Alwaleed Mohammed Lasaf', Bandar Abdullah \\ Almawash ${ }^{1}$, Fayez Hamoud Aldossary ${ }^{1}$, Aliyah Mohammed Marghalani ${ }^{3}$, Yazeed Abdulaziz Alsubaihi ${ }^{1}$ \\ 'Department of Clinical Pharmacy, College of Pharmacy, Prince Sattam bin Abdulaziz University, Al-kharj, SAUDI ARABIA. \\ 2Department of Pharmaceutical Chemistry, College of Pharmacy, Prince Sattam bin Abdulaziz University, Al-Kharj, SAUDI ARABIA. \\ ${ }^{3}$ College of Pharmacy, Taif University, Taif, SAUDI ARABIA
}

\begin{abstract}
Objectives: This study determined the current awareness and knowledge among physicians about biosimilars in Saudi Arabia. Methods: This study used a cross-sectional study design and data were acquired by the convenience sampling method. The research tool was self-developed, prevalidated and self-administered to achieve the sample size. The physicians from various parts of the country participated in the study. Both, inferential statistics with the help of descriptive statistics were applied using the Statistical Package for Social Sciences (SPSS) version 24.0 and Microsoft Excel. A p-value $<0.05$ was considered statistically significant. Results: A total of 105 practicing physicians throughout the country participated in the study. The majority of the participants were well informed and had adequate knowledge and awareness about numerous aspects of biosimilars except for the local healthcare policies and payer policies, where around half of them very aware of them. Statistically, a non-significant association
\end{abstract}

( $p$-value $>0.05$ ) was observed. Conclusion: It is concluded that the study physicians had adequate knowledge and awareness about biosimilars in Saudi Arabia. Statistically, a non-significant association $(p<0.05)$ was observed between adequate and inadequate knowledge among the studied physicians in Saudi Arabia.

Key words: Biosimilars, Physicians, Knowledge, Awareness, Saudi Arabia.

Correspondence

Dr. Muhammad Shahid Iqbal

Department of Clinical Pharmacy, College of Pharmacy, Prince Sattam bin Abdulaziz University, Al-kharj, 11942, SAUDI ARABIA.

Phone: +966-53-7014420

Email: drmmsiqbal@gmail.com

DOI: 10.5530/jyp.2020.12.76

\section{INTRODUCTION}

Biosimilars are the biologically similar products that match with their referenced therapeutic drugs. Biosimilars are quite similar in terms of activity, efficacy, safety and quality with their similar therapeutic agents. ${ }^{1}$ The regulatory approval processes of the biosimilars are different from the regular approval process of the generic medicines because biosimilars are only similar to their reference products not identical to them. ${ }^{1,2}$ The introduction of biosimilars in the pharmaceutical market is expected to decrease the impact of biologics on healthcare budgets as in many European countries, patent expiry has reached or near to. ${ }^{3,4}$ In the past two decades, the treatment pattern of several diseases has been changed after the introduction and implementation of biosimilar products. Biosimilars are quite effective among patients with chronic and severe diseases and in those patients who have failed to respond to earlier medications. ${ }^{5,6}$

European Medicines Agency (EMA) stated that the biosimilarity profile of biosimilars in terms of efficacy and safety were quite high when compared with their therapeutic drugs. On the other side, a few healthcare organizations (HCOs) believed that biosimilars were complex proteins and could never be identical similar of the therapeutics agents. ${ }^{2,7-9}$ Despite such conflicts, biosimilars are used in numerous European countries and are getting approved in the United States and the rest of the world. ${ }^{1,2}$ Cost-effectiveness, prescription patterns, dispensing practices and patients' belief about efficacy and safety of biosimilars are among the vital factors which are expressively essential to understand. ${ }^{10,11}$ Saudi Food and Drug Authority (SFDA) is mainly responsible for the approval and availability of all drugs to use in Saudi Arabia. ${ }^{12}$ In 2010, the SFDA developed and published the first guidelines regarding the registration of biosimilars in the country. ${ }^{12-15}$ Later in 2017, a further milestone was achieved by publishing guidelines about biosimilars' quality and control in Saudi Arabia. ${ }^{16}$ The biosimilars' quality consideration guidelines provide detailed information regarding biosimilars' comparability aspects, manufacturing procedures, reference medicinal formulations and their analytical methods regarding biological activity and purity. ${ }^{17-20}$

In Saudi Arabia, biosimilars have occupied a quite rapid growth trend in the pharmaceutical market with an average growth rate of $>15 \%$. This growth rate is among the highest growth rates for the pharma market share in the middle east. ${ }^{12-15}$ In 2018 , the market shares of biosimilars had crossed 1.5 billion USD which itself showed a high market potential for biosimilars in the region. ${ }^{13-17}$ In Saudi Arabia, as the biosimilars are about to capture the pharma market, hence it is essential to determine the current awareness in terms of knowledge and awareness about biosimilars among physicians in Saudi Arabia. To date, there is a lack of published data about physicians' knowledge and awareness about the required information about biosimilars. Therefore, this study aimed to explore the physicians' knowledge and awareness about biosimilars in Saudi Arabia.

\section{MATERIALS AND METHODS}

A cross-sectional study was performed among physicians currently practicing in various healthcare sectors of the country. A self-developed research tool was used to collect the data in June-August 2019. The tool 
was validated using the content and face validity approaches with the help of experts in the field. The reliability of the questionnaire was also determined. Non-probability sampling method, in the form of quota sampling, was used to recruit physicians.

The research tool had 3 parts. The first part consisted of basic information regarding their specialty, current and preferred sources of information, willingness to know about biosimilars. The second part had questions regarding the knowledge about biosimilars and the last part was about general awareness of biosimilars regarding clinical efficacy and safety, pharmacokinetic similarities, chemical and physical similarities. The physicians currently practicing in various healthcare settings in Saudi Arabia and those who gave consent were included in the study. Physicians who refused to participate and did not give consent were not included in the study. Participation in this study was voluntary among physicians. A score of 1 was credited to each correct answer and 0 for an incorrect answer. The mean cut-off for adequate knowledge was set at $60 \%$, whereby participants who scored or answered $\geq 60 \%$ correct answers were considered having adequate knowledge and those who scored or answered $<60 \%$ correct answers were considered having inadequate knowledge.

\section{Statistical analyses}

Data entry, analyses and interpretation were done using Statistical Package for Social Science (SPSS) version 24.0 and Microsoft Excel (Microsoft Corp., Redmond, WA, USA). Mean with standard deviations were determined for the continuous variables and the frequencies with percentages were determined for the categorical variables. The normality of the data was checked and association using the correlation matrix was determined by Spearman correlation test to determine differences among study physicians regarding knowledge and awareness about biosimilars. A $p$-value of $<0.05$ was considered statistically significant.

\section{RESULTS}

A total of 105 physicians participated in the study. The physicians were from different specialties, particularly from gastroenterology, endocrinology and oncology specialties. Figure 1 represents the different specialties of physicians.

Table 1: Knowledge of biosimilars among study participants, $\mathbf{N}(\%)$.

\begin{tabular}{|c|c|c|}
\hline Statements & No & Yes \\
\hline Knowledge about biosimilars & $10(9.5)$ & $95(90.5)$ \\
\hline $\begin{array}{c}\text { Access to information about comparing biosimilars } \\
\text { with reference drugs is easy }\end{array}$ & $9(8.6)$ & $96(91.4)$ \\
\hline $\begin{array}{c}\text { Switching between reference biologics and } \\
\text { biosimilars is difficult }\end{array}$ & $34(32.4)$ & $71(67.6)$ \\
\hline Dealing with safety issues of biosimilars is easy & $6(5.7)$ & $99(94.3)$ \\
\hline $\begin{array}{l}\text { Using biosimilars into clinical practice and } \\
\text { educating patients about biosimilars is easy }\end{array}$ & $15(14.3)$ & $90(85.7)$ \\
\hline $\begin{array}{l}\text { Physicians have the authority to decide a suitable } \\
\text { biosimilar for the patients }\end{array}$ & $21(20.0)$ & $84(80.0)$ \\
\hline $\begin{array}{c}\text { There is a need for establishing a reasonable } \\
\text { and scientifically justified approach to replace a } \\
\text { therapeutic drug with biosimilars }\end{array}$ & $24(22.9)$ & $81(77.1)$ \\
\hline Familiar with naming conventions of biosimilars & $58(55.2)$ & $47(44.8)$ \\
\hline $\begin{array}{l}\text { Familiar with local healthcare policies regarding } \\
\text { biosimilars }\end{array}$ & $59(56.2)$ & $46(43.8)$ \\
\hline Familiar with payer policies regarding biosimilars & $60(57.1)$ & $45(42.9)$ \\
\hline
\end{tabular}

Table 1 illustrates the knowledge about biosimilars among the study physicians. The majority of the physicians had good knowledge about biosimilars in Saudi Arabia. They were quite familiar with biosimilars' information regarding safety and efficacy when compared with therapeutic drugs, switching from therapeutic agents to the biosimilars and their naming conventions.

Figure 2 shows the sources from which the study participants usually receive information about biosimilars. They received the information from various resources, like the internet, conferences, seminars, workshops, published literature (online education and self-study materials), their colleagues, medical representatives and events organized by pharmaceutical companies and various society meetings.

The importance of information in terms of various aspects of making decisions to use biosimilars among physicians is shown in Table 2. The majority of physicians stated that for making decisions to use biosimilars need detailed information in various aspects. The believed that clinical efficacy and safety profile, pharmacokinetic similarities between reference drugs and biosimilars are important to know for them before their use.

Table 3 shows the willingness of the physicians to know more regarding biosimilars in Saudi Arabia. The majority of the respondents showed that they need to learn more about biosimilars' safety and efficacy and new developments regarding biosimilars.

Figure 3 showed the preferred methods of knowing more information regarding biosimilars among the studies physicians. The preferred methods were varied from online courses to medical conferences, symposia, workshops, product dossiers and webinars.

Table 4 demonstrates the findings of the correlation analysis among the study participants regarding knowledge and awareness of biosimilars. Statistically, a non-significant association $(p$-value $>0.05)$ was observed.

\section{DISCUSSION}

The present study evaluated knowledge and current awareness of physicians about biosimilars regarding safety, efficacy and pharmacokinetics and dynamics equivalencies for their better use in clinical practice in Saudi Arabia. According to the obtained study results,

Table 2: Awareness of physicians about biosimilars, N (\%).

\begin{tabular}{|c|c|c|}
\hline Statements & No & Yes \\
\hline $\begin{array}{l}\text { It is important to know about clinical efficacy and } \\
\text { safety between reference drugs and biosimilars }\end{array}$ & $12(11.4)$ & $93(88.6)$ \\
\hline $\begin{array}{l}\text { It is important to know about pharmacokinetic } \\
\text { similarities between reference drugs and biosimilars }\end{array}$ & $16(15.2)$ & $89(84.8)$ \\
\hline $\begin{array}{l}\text { It is important to know about chemical/physical } \\
\text { similarities between reference drugs and biosimilars }\end{array}$ & $32(30.5)$ & $73(69.5)$ \\
\hline $\begin{array}{l}\text { It is important to know about international and } \\
\text { Saudi Arabia clinical practice guidelines and } \\
\text { standards of biosimilars }\end{array}$ & $16(15.2)$ & $89(84.8)$ \\
\hline $\begin{array}{c}\text { It is important to know about clinical } \\
\text { immunogenicity data of reference drugs and } \\
\text { biosimilars }\end{array}$ & $21(20.0)$ & $84(80.0)$ \\
\hline $\begin{array}{c}\text { It is important to know about in vitro functional } \\
\text { comparison assays between reference drugs and } \\
\text { biosimilars }\end{array}$ & $24(22.9)$ & $81(77.1)$ \\
\hline $\begin{array}{l}\text { It is important to know about cost-differences } \\
\text { between reference drugs and biosimilars }\end{array}$ & $55(52.4)$ & $50(47.6)$ \\
\hline $\begin{array}{l}\text { It is important to know about recommendations of } \\
\text { colleagues and experts regarding biosimilars }\end{array}$ & $38(36.2)$ & $67(63.8)$ \\
\hline
\end{tabular}


approximately more than $50 \%$ of the study physicians were quite familiar with biosimilars and had appropriate information about biosimilars to be used in clinical practice. The results of this study also showed that the majority of the physicians (84.8\%) agreed that the studies regarding pharmacokinetic similarities between reference drugs and biosimilars are important to be conducted to have better evidence regarding their efficacy and safety. It was also observed that around $84.8 \%$ of the physicians wanted to know more about international and Saudi Arabia clinical practice guidelines and standards of practice of biosimilars. Regarding the availability of the data about the comparison of clinical immunogenicity of the reference drugs with biosimilars, a total of $80 \%$ had appropriate knowledge and believed that it is of utmost importance in clinical practice in Saudi Arabia. These findings were quite useful regarding the biosimilars' availability in the Saudi Arabian healthcare system.

According to another study conducted by C. Ventola et al. (2013) reported that around $88 \%$ of the study participants believed that it is crucial to know about a direct comparison of clinical efficacy and product safety between reference drugs and biosimilars before their use among patients. ${ }^{21}$ In their study results, they had also observed that a total of $90 \%$ of the study participants believed that studies that determine pharmacokinetic similarities between reference products and biosimilars are important before the clinical practice of biosimilars. Although our study and their study had different study populations, different study sites, different biosimilar market and different working environments, yet both of the similar findings urge the need of detailed information of various aspects about biosimilars before their actual use in clinical practice to treat various ailments by the physicians. ${ }^{14,17}$ Similarly, another study reported that the physicians' understanding of biosimilars was

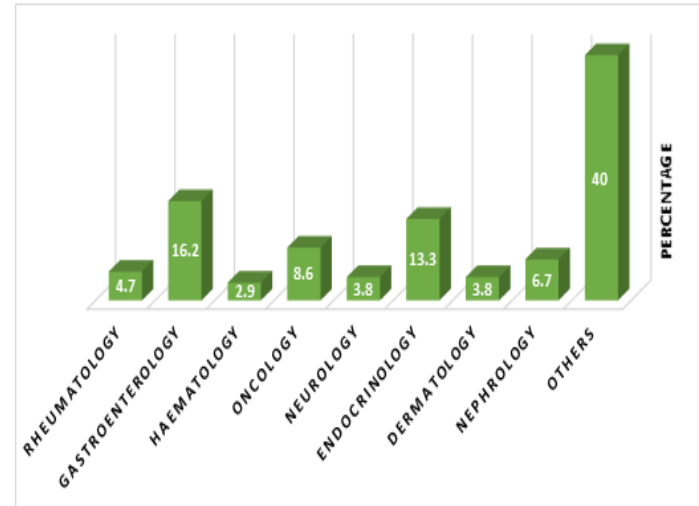

Figure 1: Specialties of the study participants.

Table 3: Willingness of the study participants to know about biosimilars.

\begin{tabular}{ccc}
\hline Statements & N & $\%$ \\
\hline I want to know more about biosimilars & 51 & 48.8 \\
$\begin{array}{c}\text { I have a basic understanding of biosimilars but would } \\
\text { like to know more about their efficacy and safety }\end{array}$ & 41 & 39.1 \\
$\begin{array}{c}\text { I am well informed about biosimilars but want to learn } \\
\text { more regarding recent developments of biosimilars } \\
\begin{array}{c}\text { I am satisfied with my current knowledge of } \\
\text { biosimilars, no further information or education } \\
\text { needed }\end{array}\end{array}$ & 13 & 12.4 \\
\hline
\end{tabular}

poor and the need to improve their awareness and knowledge regarding biosimilars was high. ${ }^{3}$ Indeed, before the actual prescribing of biosimilars, it is of utmost importance to know the efficacy, safety, cost, stability and appropriateness of biosimilars. ${ }^{3-5}$

On the other hand, around $52.4 \%$ of the studied physicians believed that information regarding the acquisition of cost-differences is important to consider while using biosimilars. This study results were similar to another study which reported that around $86 \%$ of the participants were in favor of acquiring more information regarding cost differences between the reference drugs and biosimilars. In our study, approximately $57.1 \%$ of the participants were not exactly familiar with the payer policies for the patients regarding biosimilar use. In opposition, according to another study, $87 \%$ of the participants were well familiar with the payer policies, decisions and requirements regarding biosimilar use. ${ }^{21}$

In our study, around $48.8 \%$ of the physicians showed their willingness to have overall more information regarding biosimilars use. About 39.1\% reported that they had a somewhat basic understanding of biosimilars, but they were more interested in learning about the efficacy and safety of biosimilars in Saudi Arabia. Conversely, only 12.4\% of the studied physicians believed that they were well informed about biosimilars. Even those participants who were well informed about the biosimilars they were also greatly interested to learn more regarding recent developments of biosimilars. According to another study finding, similar results were reported that the recent knowledge of the study participants about biosimilars was low and they needed to learn more about biosimilars. ${ }^{6}$ These study results highlighted the need for timely updation of the medical programs' syllabi and the regular arrangement of the continuous medical education programs to better equip the physicians with the

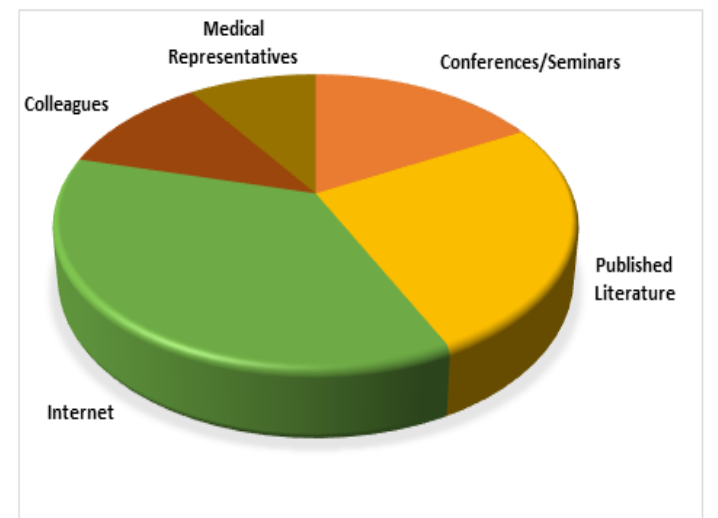

Figure 2: Participants' information sources about biosimilars.

Table 4: Statistical correlation between adequate and inadequate knowledge about biosimilars.

\begin{tabular}{ccc}
\hline No. & Statements & $p$-value \\
\hline 1 & Biosimilars knowledge & 0.364 \\
2 & Comparing biosimilars with reference drugs & 0.409 \\
3 & Safety of biosimilars & 0.189 \\
4 & Biosimilars' use and patients education & 0.277 \\
5 & Clinical efficacy of biosimilars & 0.558 \\
6 & Pharmacokinetic profile of biosimilars & 0.098 \\
7 & International and Saudi Arabia guidelines of biosimilars & 0.753 \\
\hline
\end{tabular}

* Statistical correlation is significant at 0.05 level (2-tailed) 


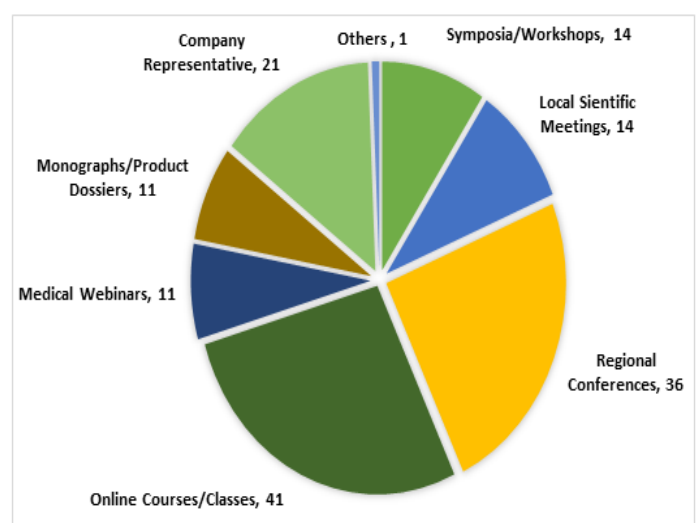

Figure 3: The preferred ways to learn more about biosimilars (N).

recent knowledge and detailed information about biosimilars in the local market. ${ }^{13-15}$

In this study, regarding the preferred modes/ways of learning about biosimilars, the preferred education format to learn and know more about biosimilars were online educational programs (39\%) followed by regional scientific conferences and meetings (13.3\%). In contrast to our findings, another study reported that the preferred education format among their study physicians was physical conferences and other live meetings. ${ }^{18}$ Regarding the rest of the preferred learning methods among the participants in our study, symposia and workshops (13.3\%), regional conferences (34.3\%), medical webinars (10.5\%) and by company representatives (20\%) were observed. In terms of the association between the inadequate to adequate response ratio (10:90) regarding knowledge and awareness of biosimilars among the studies physicians, statistically, a non-significant association ( $p$-value $>0.05$ ) was observed.

Irrefutably, physicians' knowledge and awareness regarding safety, efficacy, similarity and cost-effectiveness of the biosimilars is significantly vital to obtain better treatment outcomes, enhanced patients' safety and deliver optimum pharmacotherapy. ${ }^{22,23}$ Incorrect use of biosimilars among patients may cause adverse events which can affect patients' health-related quality of life. ${ }^{24-26}$ Likewise, it is also the responsibility of the biosimilar manufacturing companies to be cautious and focused during biosimilar production especially in their safety, efficacy and quality control. ${ }^{26-28}$

\section{CONCLUSION}

The present study concluded that knowledge and awareness about biosimilars among physicians are important. The current findings show that most of the physicians had good understandings in terms of knowledge and awareness of biosimilars in Saudi Arabia. In the near future, biosimilars could play a vital role in the cost-effective management of numerous chronic diseases if healthcare professionals are very well informed about their efficacy, safety and proper use.

\section{ACKNOWLEDGEMENT}

The authors would like to thank the Deanship of Scientific Research at Prince Sattam bin Abdulaziz University, Alkharj, Saudi Arabia for the support in the publication of this manuscript. The authors would also like to express their sincere gratitude to all of the participants involved in this study in any capacity.

\section{CONFLICT OF INTEREST}

The authors declare no conflict of interest.

\section{ABBREVIATIONS}

EMA: European Medicines Agency; HCOs: Healthcare Organizations; SFDA: Saudi Food and Drug Authority; SPSS: Statistical Package for Social Sciences; USD: United States Dollar.

\section{REFERENCES}

1. US Food and Drug Administration. Scientific considerations in demonstrating biosimilarity to a reference product: Guidance for industry. Available: https:// www.fda.gov/regulatory-information/search-fda-guidance-documents/ scientific-considerations-demonstrating-biosimilarity-reference-product

2. European Medicines Agency (EMA). Guideline on similar biological medicinal products containing monoclonal antibodies - non-clinical and clinical issues. 2012. http://www.ema.europa.eu/docs/en_GB/document_library/Scientific_ guideline/2012/06/WC500128686.pdf.

3. Cohen $H$, Beydoun D, Chien D, Lessor T, McCabe D, Muenzberg M, et al. Awareness, knowledge and perceptions of biosimilars among specialty physicians. Advances in Therapy. 2017;33(12): 2160-72.

4. Biosimilar medicines: overview. 2017. https://www.ema.europa.eu/en/humanregulatory/overview/biosimilar-medicines

5. Cook JW, McGrath MK, Dixon MD, Switchenko JM, Harvey RD, Pentz RD. Academic oncology clinicians' understanding of biosimilars and information needed before prescribing. Ther Adv Med Oncol. 2019;11:1758835918818335.

6. Micó-Pérez RM, et al. Knowledge about Biosimilars in Primary Care: A study by the Spanish Society of Primary Care Physicians (SEMERGEN). Semergen. 2018;44(6):380-8.

7. Sieczkowska-Golub J, Jarzebicka D, Oracz G, Kierkus J. Biosimilars in paediatric inflammatory bowel disease. World Journal of Gastroenterology. 2018;24(35):4021-7.

8. US Food and Drug Administration. Biosimilar and Interchangeable Biologics: More Treatment Choices. 2017. https://www.fda.gov/consumers/consumerupdates/biosimilar-and-interchangeable-biologics-more-treatment-choices

9. O'Callaghan J, Bermingham M, Leonard M, Hallinan F, Morris JM, Moore U, et al. Assessing awareness and attitudes of healthcare professionals on the use of biosimilar medicines: A survey of physicians and pharmacists in Ireland. Regulatory Toxicology and Pharmacology. 2017;88:252-61.

10. Aladul MI, Fitzpatrick RW, Chapman SR. The effect of new biosimilars in rheumatology and gastroenterology specialities on UK healthcare budgets: Results of a budget impact analysis. Res Social Adm Pharm. 2019;15(3):310-7.

11. Jha A, Upton A, Dunlop WC, et al. The budget impact of biosimilar infliximab (Remsima $®$ ) for the treatment of autoimmune diseases in five European countries. Adv Ther. 2015;32(8):742-56

12. Tariq MA, Hatem AA, Mansour A, Mansour AM, Ahmed A, Yazed SA, et al. Advancing pharmaceuticals and patient safety in Saudi Arabia: A 2030 vision initiative. Saudi Pharmaceutical Journal. 2018;26(1):71-4.

13. Wajid S, Al-Arifi M, AINomay H, AlMousa Y, Babelghaith S. Knowledge and perception of community pharmacists' towards generic medicines in Saudi Arabia. Biomedical Research. 2015;26(4):800-6.

14. Almohammed OA, Aldwihi LA, Alhifany AA. Public knowledge, perception and experience with generic medications in Saudi Arabia. Saudi Medical Journal. 2020;41(4):413-20.

15. Alkhuzaee FS, Almalki HM, Attar AY, Althubiani SI, Almuallim W, Cheema E, et al. Evaluating community pharmacists' perspectives and practices concerning generic medicines substitution in Saudi Arabia: A cross-sectional study. Health Policy. 2016;120(12):1412-9.

16. Saudi Food and Drug Authority, Drug Sector, Guideline on Biosimilar Products, Quality considerations. 2007. https://old.sfda.gov.sa/ar/drug/resources/DocLib2/ Guideline-on-biosimilar-products.pdf

17. Salhia HO, Ali A, Rezk NL, EIMetwally A. Perception and attitude of physicians toward local generic medicines in Saudi Arabia: A questionnaire-based study. Saudi Pharmaceutical Journal. 2015;23(4):397-404.

18. Karateev D, Belokoneva N. Evaluation of Physicians' Knowledge and Attitudes Towards Biosimilars in Russia and Issues Associated with Their Prescribing. Biomolecules. 2019;9(2):57.

19. Wiland P, Batko B, Brzosko M, Kucharz EJ, Samborski W, Świerkot J, et al. Biosimilar switching-current state of knowledge. Reumatologia. 2018;56(4):234-42.

20. Simon Kucher and Partners. Payers' price and market access policies supporting a sustainable biosimilar medicines market. 2016. https://www. medicinesforeurope.com/wp-content/uploads/2016/09/Simon-Kucher-2016Policy-requirements-for-a-sustainable-biosimilar-market-FINAL-report_forpublication2.pdf.

21. Ventola CL. Biosimilars part 2: Potential concerns and challenges for $P \& T$ committees. PT. 2013;38(6):329-35

22. Kim H, Alten R, Avedano L, et al. The Future of Biosimilars: Maximizing Benefits Across Immune-Mediated Inflammatory Diseases. Drugs. 2020;80(2):99-113.

23. Háda V, Bagdi A, Bihari Z, Timári SB, Fizil Á, Szántay JC. Recent advancements, 
challenges and practical considerations in the mass spectrometry-based analytics of protein biotherapeutics: A viewpoint from the biosimilar industry. Journal of Pharmaceutical and Biomedical Analysis. 2018;161:214-38.

24. Kristensen LE, Alten R, Puig L, Philipp S, Kvien TK, Mangues MA, et al. Nonpharmacological effects in switching medication: the nocebo effect in switching from originator to biosimilar agent. Bio Drugs. 2018;32(5):397-404.

25. Kumar R, Sigala S, Malgarini RB, Pimpinella G, Pani L, Pecorelli S, et al. Biosimilars: Regulatory status and implications across the world. J
Pharmacovigilance. 2015;S3:002.

26. Daller J. Biosimilars: A consideration of the regulations in the United States and European Union. Regul Toxicol Pharmacol. 2016;76:199-208.

27. Stevenson JG, Green L. Biologics, pharmacovigilance and patient safety: it's all in the name. J Manag Care Spec Pharm. 2016;22(8):927-30.

28. Grabowski D, Henderson B, Lam D, Keystone EC, Thorne C, Jamal S, et al. Attitudes towards subsequent entry biologics/biosimilars: A survey of Canadian rheumatologists. Clin Rheumatol. 2015;34(8):1427-33.

Article History: Submission Date :11-06-2020; Revised Date : 18-07-2020; Acceptance Date : 27-08-2020

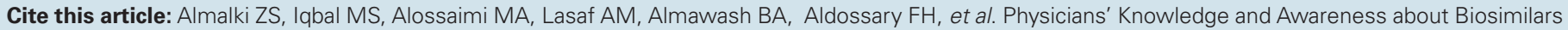
in Saudi Arabia: What is Imperative to Know. J Young Pharm. 2020;12(3):280-4. 